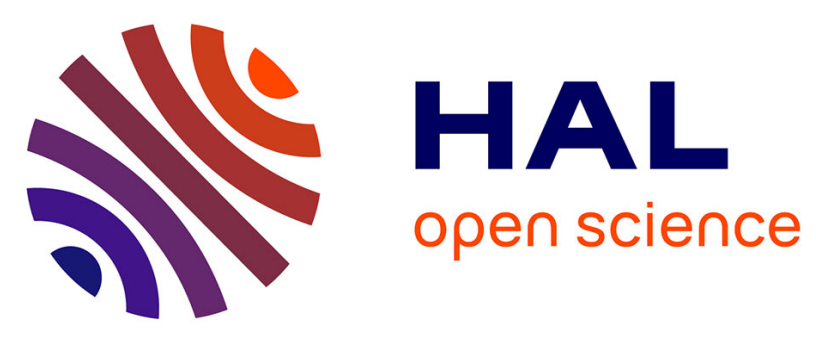

\title{
Theoretical and photo-electrochemical studies of surface plasmon induced visible light absorption of Ag loaded TiO 2 nanotubes for water splitting
}

P. Gross, N. Javahiraly, N. Geraldini Sabat, Thomas Cottineau, E. R Savinova, V. Keller

\section{To cite this version:}

P. Gross, N. Javahiraly, N. Geraldini Sabat, Thomas Cottineau, E. R Savinova, et al.. Theoretical and photo-electrochemical studies of surface plasmon induced visible light absorption of $\mathrm{Ag}$ loaded TiO 2 nanotubes for water splitting. Applied Physics Letters, 2016, 109 (15), pp.153903. 10.1063/1.4964827 . hal-02384149

HAL Id: hal-02384149

https://hal.science/hal-02384149

Submitted on 28 Nov 2019

HAL is a multi-disciplinary open access archive for the deposit and dissemination of scientific research documents, whether they are published or not. The documents may come from teaching and research institutions in France or abroad, or from public or private research centers.
L'archive ouverte pluridisciplinaire HAL, est destinée au dépôt et à la diffusion de documents scientifiques de niveau recherche, publiés ou non, émanant des établissements d'enseignement et de recherche français ou étrangers, des laboratoires publics ou privés. 
Theoretical and photo-electrochemical studies of surface plasmon induced visible light absorption of $\mathrm{Ag}$ loaded $\mathrm{TiO}_{2}$ nanotubes for water splitting

P. A. Gross', N. Javahiraly, N. Geraldini Sabat, T. Cottineau, E. R. Savinova, and V. Keller

Citation: Appl. Phys. Lett. 109, 153903 (2016); doi: 10.1063/1.4964827

View online: http://dx.doi.org/10.1063/1.4964827

View Table of Contents: http://aip.scitation.org/toc/apl/109/15

Published by the American Institute of Physics

\section{Articles you may be interested in}

Research Update: Strategies for efficient photoelectrochemical water splitting using metal oxide photoanodes Appl. Phys. Lett. 2, 010703010703 (2014); 10.1063/1.4861798

Research Update: Photoelectrochemical water splitting and photocatalytic hydrogen production using ferrites (MFe2O4) under visible light irradiation

Appl. Phys. Lett. 3, 104001104001 (2015); 10.1063/1.4931763

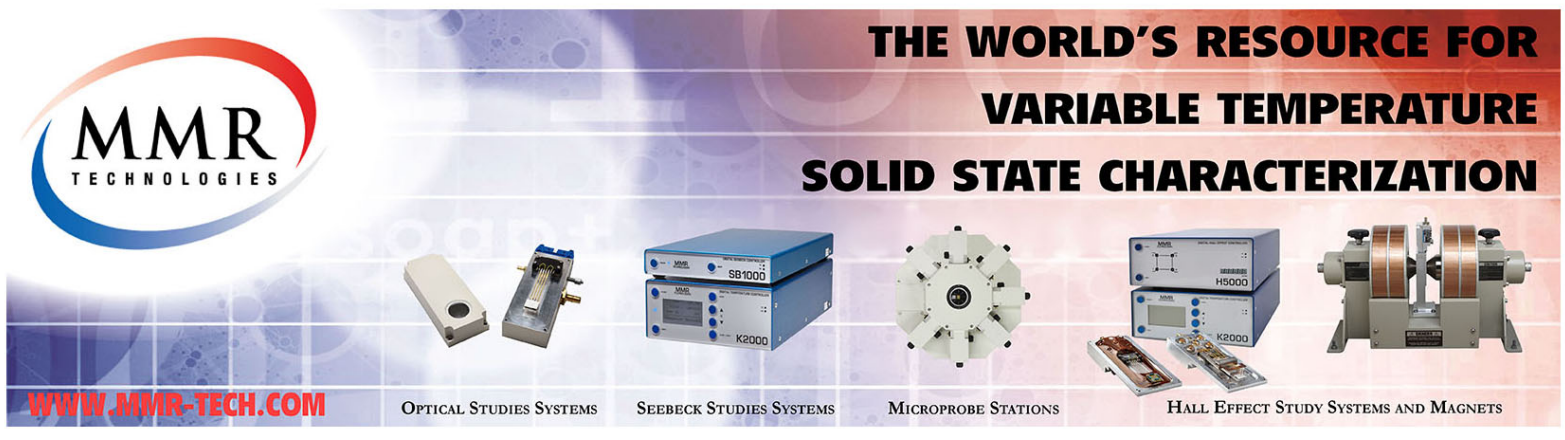




\title{
Theoretical and photo-electrochemical studies of surface plasmon induced visible light absorption of $\mathrm{Ag}$ loaded $\mathrm{TiO}_{2}$ nanotubes for water splitting
}

\author{
P. A. Gross, ${ }^{1,2, a)}$ N. Javahiraly, ${ }^{3}$ N. Geraldini Sabat, ${ }^{1}$ T. Cottineau, ${ }^{1}$ E. R. Savinova, ${ }^{1}$ \\ and V. Keller ${ }^{1}$ \\ ${ }^{1}$ ICPEES, UMR7515, 25 rue Becquerel, 67087 Strasbourg, France \\ ${ }^{2}$ Stanford Microsystems Laboratory, 452 Escondido Mall, Stanford, California 94043, USA \\ ${ }^{3}$ ICube, UMR 7357, 300 bd Sébastien Brant, CS 10413, 67412 Illkirch, France
}

(Received 6 July 2016; accepted 1 October 2016; published online 14 October 2016)

\begin{abstract}
Vertically aligned $\mathrm{TiO}_{2}$ nanotubes $\left(\mathrm{TiO}_{2}\right.$-NTs), obtained by anodization in organic electrolyte, are decorated with $15 \mathrm{~nm} \mathrm{Ag} \mathrm{nanoparticles} \mathrm{prepared} \mathrm{by} \mathrm{a} \mathrm{micro-wave} \mathrm{assisted} \mathrm{polyol} \mathrm{synthesis.} \mathrm{The}$ $\mathrm{Ag} / \mathrm{TiO}_{2}$ system is characterized by electronic microscopies in order to build a Finite Differential Time Domain (FDTD) model to simulate the interaction of light with the system. By combining UV-visible spectroscopy and FDTD simulations, the observed red shift in the surface plasmon resonance wavelength of the Ag nanoparticles, deposited on $\mathrm{TiO}_{2}$, is explained. The $\mathrm{Ag} / \mathrm{TiO}_{2}-\mathrm{NT}$ system is used as photoanode in a photoelectrochemical water splitting setup and shows an increasing Incident Photon to Current Conversion Efficiency (IPCE) in the visible light domain with an increasing amount of deposited Ag. The spectral position of this activity enhancement coincides with the one expected from the FDTD calculations for the surface plasmon resonance of the Ag nanoparticles deposited on $\mathrm{TiO}_{2}$. Published by AIP Publishing. [http://dx.doi.org/10.1063/1.4964827]
\end{abstract}

Vertically aligned $\mathrm{TiO}_{2}$ nanotubes $\left(\mathrm{TiO}_{2}-\mathrm{NTs}\right)$ grown on top of a conductive substrate by electrochemical anodization have attracted much interest since they have been discovered in the early 2000s. ${ }^{1-3}$ They are now used as photoanodes either in the photoelectrochemical cell proposed in the $70 \mathrm{~s}$ by Fujishima and Honda for water-splitting ${ }^{4}$ or for the photooxidation of various organic pollutants. ${ }^{5}$ The main drawback of this material comes from the large band gap of $\mathrm{TiO}_{2}$ of $3.2 \mathrm{eV}$, for the anatase phase, limiting its photoelectrochemical conversion to UV light $(\lambda<390 \mathrm{~nm})$.

Several approaches are investigated to extend the absorption spectrum of $\mathrm{TiO}_{2}$ to the visible part of the solar spectrum. However, there is up to now no ultimate technique and some drawbacks are always present. A well studied one is chemical doping by the substitution of $\mathrm{O}^{2-}$ anions by $\mathrm{C}^{4-}, \mathrm{N}^{3-}$, and $\mathrm{F}^{-6,7}$ allowing the absorption of larger wavelengths often at the price of increasing electron/hole pairs recombination. ${ }^{8}$ Another way is the coupling of $\mathrm{TiO}_{2}$ with organic dyes, as proposed by Grätzel. ${ }^{9}$ These molecules allow absorbing a large portion of the solar spectrum but are sometimes sensitive to degradation and oxidation. One can also cite the formation of heterojunctions, with either a polymeric semiconducting material, ${ }^{10}$ acting as a photosensitizer, or another metal oxide semiconductor with a smaller band gap than $\mathrm{TiO}_{2} \cdot{ }^{11}$ Finally, the approach studied in the present paper is the functionalization of the semiconductor with metallic nanoparticles to make use of their plasmonic properties, ${ }^{12-14}$ such as $\mathrm{Au}^{15,16}$ and $\mathrm{Ag} .{ }^{17,18} \mathrm{We}$ choose to work on this approach because the metallic nanoparticles are more resistant to experimental conditions, are easy to synthesize and have both catalytic and optical interesting properties.

In this paper, we focus on the functionalization of $\mathrm{TiO}_{2}$ nanotubes with the $\mathrm{Ag}$ nanoparticles having a surface

\footnotetext{
${ }^{\text {a) }}$ Author to whom correspondence should be addressed. Electronic mail: pialgr@stanford.edu
}

plasmon resonance (SPR) peak in the blue part of the visible spectrum, i.e., close to the $\mathrm{TiO}_{2}$ band gap energy. The energy transfer mechanism between a surface plasmon activated metallic nanoparticle and a semiconducting material is now explained as comprising two main mechanisms that are still frequently discussed. The first is the SPR-mediated charge injection from the metal to the semiconductor, ${ }^{19}$ and the second is the near-field enhancement of the electrical field. ${ }^{20}$ According to the cited papers, those mechanisms can occur simultaneously.

We built an FDTD (Finite Differential Time Domain) model, derived from the experimental parameters, to give insight into the behavior of this particular interface between SPR-activated Ag nanoparticles and $\mathrm{TiO}_{2}$ when under illumination. The FDTD calculations are based on the resolution of the Maxwell equations in time domain. The model leads to several information (field exaltations, transmission, and so on) necessary to study the wave propagation in different materials for different nanostructured systems. ${ }^{21}$ The results are then compared with the experimental results obtained by the UV-visible spectroscopy and photoelectrocatalytic (PEC) measurements.

First, the $\mathrm{TiO}_{2}$-NT electrodes are prepared by electrochemical anodization and then characterized by scanning electron microscopy (SEM) $\left(\right.$ Jeol $^{\circledR}$ JSM-6700 F), transmission electron microscopy (TEM) $\left(\right.$ Jeol $\left.^{\circledR} 2100 \mathrm{~F}\right)$, and X-ray diffraction (XRD) (Brucker ${ }^{\circledR}$ D8 Advance). The experimental parameters for the synthesis are available in the supplementary material. The detailed growth mechanism of these nanostructures is well described in several reviews. ${ }^{22-24}$

The Ag nanoparticles are prepared by a micro-wave assisted polyol synthesis with PVP (Polyvinylpyrrolidone) as capping agent. Synthesis parameters are detailed in the supplementary material as well, and growth mechanism can be found in the literature. ${ }^{12,25}$ The as prepared Ag nanoparticles 
are deposited by drop casting on the surface of vertically aligned $\mathrm{TiO}_{2}$-NTs. The absorption behavior of the $\mathrm{Ag} / \mathrm{TiO}_{2}$ NT system is studied both experimentally and by FDTD simulations. The parameters of the model for the FDTD simulation are determined by the results obtained by the characterization of the $\mathrm{TiO}_{2}$-NTs and the Ag nanoparticles with SEM, TEM and UV-visible spectroscopy. The calculations are performed with the FDTD- Lumerical $^{\circledR}$ software and were focused on the light absorption properties of the system.

Fig. 1(a) shows an SEM image of the $\mathrm{TiO}_{2}$-NTs after annealing under air for $5 \mathrm{~h}$ at $550^{\circ} \mathrm{C}$. The length of the nanotubes is $3.7 \pm 0.2 \mu \mathrm{m}$, the inner diameter is $50 \pm 5 \mathrm{~nm}$ and the outer diameter is $105 \pm 5 \mathrm{~nm}$. Those dimensions are the ones used to design the FDTD model. The $\mathrm{TiO}_{2}$ nanotubes were also characterized by XRD, and the results are presented in the supplementary material.

Fig. 1(b) shows a TEM image of the resulting Ag colloidal solution. The Ag colloidal solution is composed of spherical nanoparticles with an average size of $15.4 \mathrm{~nm}$ and a standard deviation of $4.6 \mathrm{~nm}$. This size distribution is in good accordance with the work of Komarneni et al. ${ }^{26}$ who used similar synthesis conditions. From these observations, we used the spherical Ag nanoparticles with a diameter of $15 \mathrm{~nm}$ to build the FDTD model.

The as prepared Ag colloids in water are characterized by the Inductive Coupled Plasma-Atomic Emission Spectroscopy (ICP-AES) to determine the concentration of $\mathrm{Ag}$ in order to make mass controlled deposits on the $\mathrm{TiO}_{2}-\mathrm{NT}$ layer. Determined concentration of the colloid is $198 \mathrm{mg}$ of $\mathrm{Ag}$ per
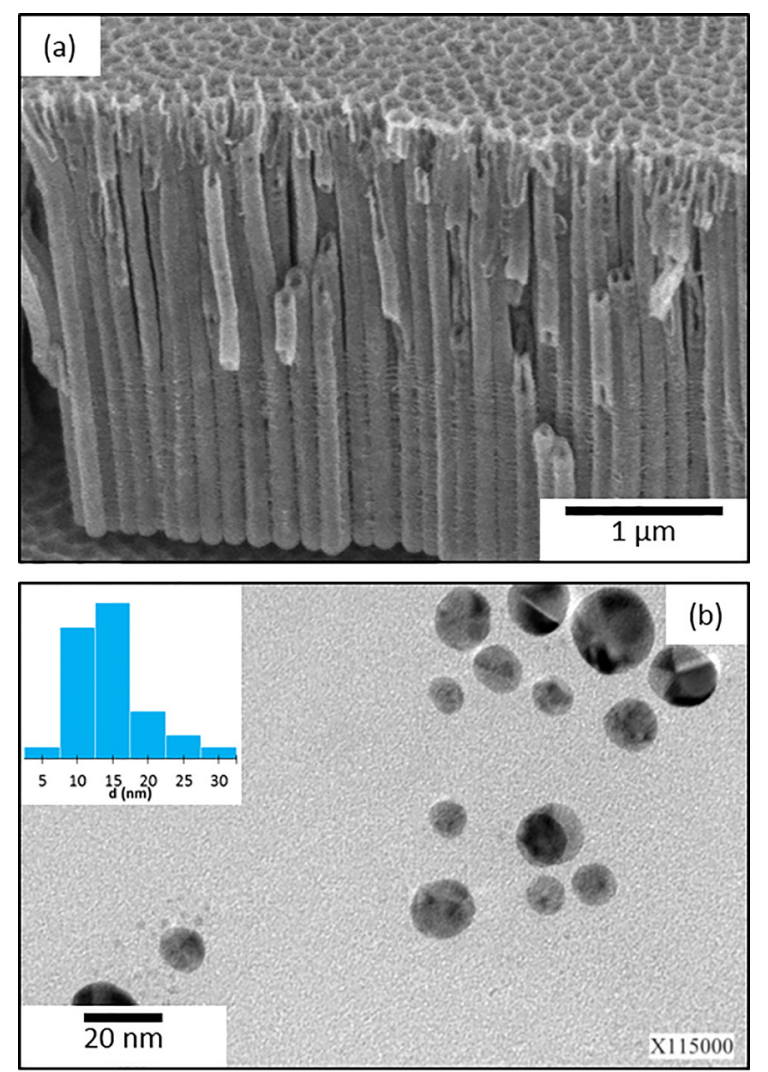

FIG. 1. SEM image of the $\mathrm{TiO}_{2}$-NTs (a). TEM image of the as prepared Ag colloid after washing treatment: inset is the corresponding size distribution in nm, measured on several images (b). $\mathrm{kg}$ of colloidal solution. With an original mass of $\mathrm{AgNO}_{3}$ of $0.003 \mathrm{~g}\left(0.0044 \mathrm{~mol} \cdot \mathrm{L}^{-1}\right)$ used for the synthesis, the yield of the reaction is $41 \%$. The deposits of different mass of $\mathrm{Ag}$ between $0.05 \mathrm{wt} . \%$ and $1.0 \mathrm{wt}$. \% were made by drop casting. Evaporation of the solvent is made at $80^{\circ} \mathrm{C}$. Fig. 2(a) shows TEM images of a portion of the $\mathrm{TiO}_{2}$-NT film exhibiting $\mathrm{Ag}$ nanoparticles, which seem to be located on the internal tube walls.

The Ag nanoparticles colloid and $\mathrm{TiO}_{2}$-NTs with various loadings of $\mathrm{Ag}$ are then analyzed by the UV-visible spectroscopy (Varian $^{\mathbb{B}} 100$ spectrometer). The Ag colloidal solution was characterized in the transmission mode, and the $\mathrm{TiO}_{2^{-}}$ NTs in diffuse reflectance configuration using Labsphere ${ }^{\circledR}$ DRA-CA-301. The reflectance signal (R) for the $\mathrm{TiO}_{2}-\mathrm{NTs}$ is used to obtain the Kubelka-Munk function $F(R)$ with Equation (1). The Kubelka-Munk is similar to the absorption for solids but takes into account the reference spectra ${ }^{27}$

$$
\mathrm{F}(\mathrm{R})=\frac{(1-\mathrm{R})^{2}}{2 \mathrm{R}} .
$$

Fig. 3(a) shows the resulting spectrum for the Ag colloid (black dashed line). The curve is composed of a single absorption peak, which corresponds to the surface plasmon resonance peak, and is centered at $402 \mathrm{~nm}$. The position of the peak is coherent for the shape and size of Ag nanoparticles in water. ${ }^{12,26}$

Fig. 3(a) also shows the Kubelka-Munk curves $(F(R))$, derived from reflectance spectra, of the $\mathrm{TiO}_{2}$-NTs before (black line) and after (colored lines) deposition of various masses of Ag. All the $\mathrm{TiO}_{2}$-NT samples, with and without Ag, show a main absorption edge starting at $390 \mathrm{~nm}$. This corresponds to the $\mathrm{TiO}_{2}$-anatase band gap of $3.2 \mathrm{eV}$, as confirmed by the Tauc curves $^{28}$ (not shown here) derived from the UVvisible spectra. The spectra reach a maximum at $360 \mathrm{~nm}$ and exhibit oscillations at $\lambda>450 \mathrm{~nm}$ coming from the interferences of the light beam with the thin $\mathrm{TiO}_{2}$-NT layer. ${ }^{23}$

The curves for the same sample but with increasing amount of deposited Ag exhibit an absorption shoulder, which tends to increase until 1.0 wt. \% of deposited Ag. This absorption, resulting from the presence of the $\mathrm{Ag}$ nanoparticles, reaches a maximum at $440 \mathrm{~nm}$, which is coherent with the observation made by Yang et al. ${ }^{29}$ with a similar system. The position of this absorption shoulder is nevertheless redshifted compared to the position of the absorption peak for the Ag colloidal solution in water (dashed black line).

To explain this red shift, three FDTD simulations have been performed on a single $15 \mathrm{~nm} \mathrm{Ag}$ spherical nanoparticle in the continuous media of $\mathrm{H}_{2} \mathrm{O}, \mathrm{PVP}$ and $\mathrm{TiO}_{2}$. The resulting curves are presented in Fig. 3(b). In order to perform all the FDTD simulations, the real and imaginary parts of the dielectric constants of Ag were obtained using Equations (1) and (2) with the values of refractive index $n$ and extinction coefficient $k$ measured by Johnson and Christy ${ }^{30}$

$$
\begin{gathered}
\varepsilon_{1}=\mathrm{n}^{2}-\mathrm{k}^{2}, \\
\varepsilon_{2}=2 \mathrm{nk} .
\end{gathered}
$$

For the surrounding media, the values of the dielectric constants were found in the literature: $\varepsilon_{\mathrm{m}}(\mathrm{PVP})=2.25$ (Ref. 31) 


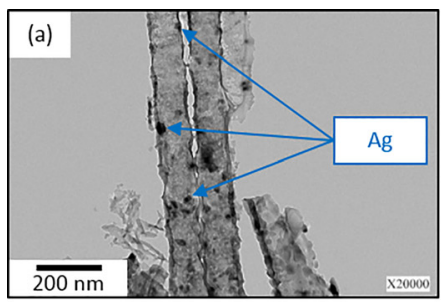

(b)

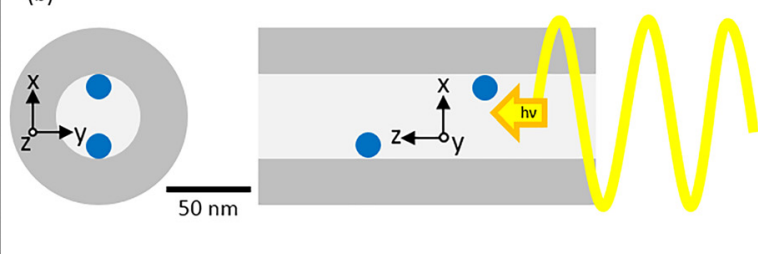

FIG. 2. TEM image of $\mathrm{TiO}_{2}$ nanotubes after deposition of 1.0 wt. \% of $\mathrm{Ag}$ nanoparticles (a). Proposed FDTD model for the $\mathrm{Ag} / \mathrm{TiO}_{2}$ system (b). and in the work of Landmann et al. ${ }^{32}$ for $\mathrm{TiO}_{2}$ anatase. For $\mathrm{H}_{2} \mathrm{O}$, the dielectric constant of the FDTD software was used, $\varepsilon_{\mathrm{m}}\left(\mathrm{H}_{2} \mathrm{O}\right)=1.77$.

The resulting simulated spectra show absorption peaks at $388 \mathrm{~nm}, 413 \mathrm{~nm}$ and $550 \mathrm{~nm}$, respectively, for the $\mathrm{Ag}$ nanoparticle embedded in $\mathrm{H}_{2} \mathrm{O}, \mathrm{PVP}$ and $\mathrm{TiO}_{2}$ anatase. In the case of $\mathrm{Ag}$ embedded in $\mathrm{TiO}_{2}$-anatase (purple dashed line), the curve also exhibits an absorption edge starting at $470 \mathrm{~nm}$ that corresponds to the absorption of the $\mathrm{TiO}_{2}$ medium. For Ag in PVP, the position of the simulated absorption peak is slightly red shifted compared to the experimental absorption peak of the Ag colloid (Fig. 3(a), black dashed line) centered on $403 \mathrm{~nm}$. This is probably because in the experimental case the PVP layer is only a few nanometers thick; thus, the water from the colloid has an impact
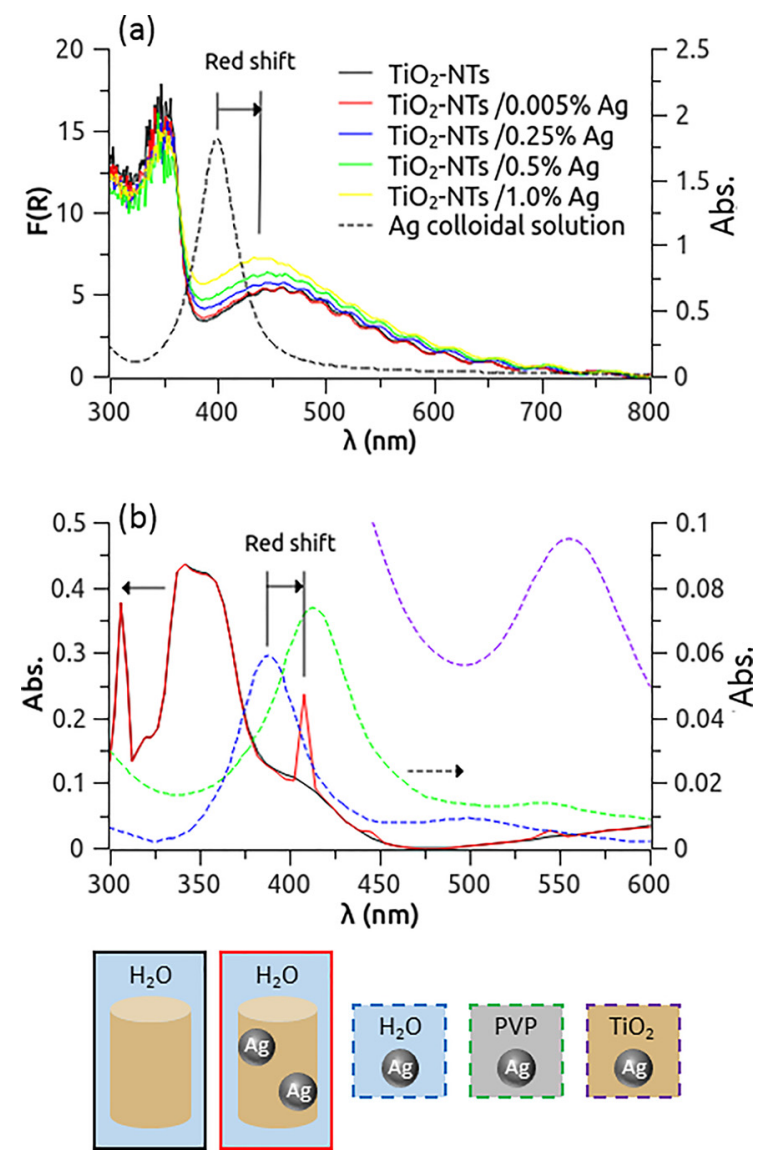

FIG. 3. Absorption spectra of $\mathrm{TiO}_{2}$ nanotubes with different amounts of deposited Ag (plain lines) and UV-visible spectrum of the Ag colloidal solution in water (dashed line) (a). FDTD absorption spectra of an empty $\mathrm{TiO}_{2}$ tube (black line), the $\mathrm{Ag} / \mathrm{TiO}_{2}$ system (red line) and a single $\mathrm{Ag}$ nanoparticle in different continuous media (blue, green, and purple dashed lines). The schemes represent the different FDTD simulation corresponding to each curve (b). (blue shift) on the position of the peak, unlike the situation in the simulation with a continuous medium of PVP. In the case of the $\mathrm{Ag}$ nanoparticle in $\mathrm{TiO}_{2}$-anatase, the simulated absorption peak is strongly red-shifted, which shows how the position of the plasmon resonance band is strongly dependent on the surrounding medium. The increasing absorption shoulder observed on the experimental spectrum for the $\mathrm{Ag}$ loaded $\mathrm{TiO}_{2}$-NT samples (Fig. 3(a)) is positioned in between these two extreme cases ( $\mathrm{Ag}$ in PVP and $\mathrm{Ag}$ in $\mathrm{TiO}_{2}$ ) at $440 \mathrm{~nm}$. This is due to the fact that the chemical environment of the Ag nanoparticles, when deposited on the $\mathrm{TiO}_{2}-\mathrm{NTs}$, is composed mainly of PVP, but also of $\mathrm{TiO}_{2}$. This explains why the absorption coming from the $\mathrm{Ag}$, when it is deposited on the $\mathrm{TiO}_{2}$-NTs, is red-shifted compared to absorption of the colloidal solution.

Fig. 2(b) depicts the model for the $\mathrm{Ag} / \mathrm{TiO}_{2}$ system used for the FDTD calculations. This model has been built according to the TEM observations of the $\mathrm{TiO}_{2}-\mathrm{NTs} / 1.0 \%$ $\mathrm{Ag}$ sample, where the number of Ag particles per $\mu \mathrm{m}$ of $\mathrm{TiO}_{2}$-NTs has been estimated to be 8 giving an average spacing between the nanoparticles of $70 \mathrm{~nm}$. The FDTD model is built as follows: i) a $200 \mathrm{~nm}$ long and $100 \mathrm{~nm}$ in diameter $\mathrm{TiO}_{2}$-anatase Tube with a wall thickness of $50 \mathrm{~nm}$, and ii) two $15 \mathrm{~nm}$ spherical Ag nanoparticles sitting on the inner wall of the tube. The two nanoparticles are separated by $70 \mathrm{~nm}$. The system is illuminated by a plane wave that propagates along the $z$ axis.

Fig. 3(b) also shows the absorption spectra obtained by the FDTD calculations for an empty $\mathrm{TiO}_{2}$-anatase tube (black line). The curve shows a main absorption edge that starts at $380 \mathrm{~nm}$ and reaches a maximum of absorption at $350 \mathrm{~nm}$, which is coherent for $\mathrm{TiO}_{2}$, and is in good accordance with the experimental results obtained on Fig. 3(a) for the unmodified $\mathrm{TiO}_{2}-\mathrm{NT}$ samples. For the $\mathrm{Ag} / \mathrm{TiO}{ }_{2}$ system (red line), the only difference in the absorption spectrum compared to the $\mathrm{TiO}_{2}$ tube alone is the presence of a sharp absorption peak located at $408 \mathrm{~nm}$, which is attributed to the plasmonic resonance of the Ag nanoparticles present inside the tube. This peak is very sharp compared to the absorption shoulder observed on the UV-visible spectra, but this is due to the fact that in the FDTD model the Ag nanoparticles are perfectly spherical and have exactly the same size, whereas the colloidal solution contains a distribution of Ag nanoparticles with different sizes. Moreover, in the $\mathrm{Ag} / \mathrm{TiO}_{2}$ samples, the Ag nanoparticles have also a position distribution and can sit on the internal or external surface of the nanotubes. Nevertheless, the position of this peak is red-shifted compared to the peak observed for the single Ag nanoparticle surrounded by water (blue dashed line) due to the presence of $\mathrm{TiO}_{2}$ in the environment of the $\mathrm{Ag}$ nanoparticles. 
The presence of this red-shift in the FDTD simulation is in good accordance with the one observed on the experimental curves from the Fig. 3(a).

The $\mathrm{TiO}_{2}$-NT electrodes with various $\mathrm{Ag}$ loadings are then used as photoanodes in a photoelectrochemical water splitting setup for hydrogen generation. Details about the measurements of the photoelectrocatalytic activity are presented in the supplementary material.

Fig. 4(a) shows the results for the Incident Photon to Current Conversion Efficiency (IPCE) measurements for $\mathrm{TiO}_{2}$-NT (black line) and $\mathrm{Ag} / \mathrm{TiO}_{2}-\mathrm{NT}$ photoanodes (color lines). The curves show a main activity edge starting at $400 \mathrm{~nm}$ that is coherent with the absorption results from Fig. 3(a). The IPCE reaches a $15 \%$ maximum at $300 \mathrm{~nm}$ for the unmodified $\mathrm{TiO}_{2}$-NT electrodes. When $\mathrm{Ag}$ is present, however, the curve exhibits a peak at $360 \mathrm{~nm}$ followed by a plateau. The presence of this peak can originate from the filling of surface states induced by the presence of Ag and/or PVP at the interface with the nanoparticles. This increase in photocurrent is then due to a diminution of electron/hole pairs recombination because holes are used either to fill these states, located above the valence band, or to oxidize the PVP present on the Ag nanoparticles.

However, the FDTD simulations showed that the main contribution of $\mathrm{Ag}$ was located at $408 \mathrm{~nm}$ and no particular activity enhancement is observed at that particular wavelength. First, it is probably due to the large activity of the $\mathrm{TiO}_{2}$ in that region that is probably hiding any contribution made by the Ag SPR. Also, it is important to point out the differences between the FDTD model and the experimental situation. In the first case, the $\mathrm{TiO}_{2}$ tube is perfectly smooth
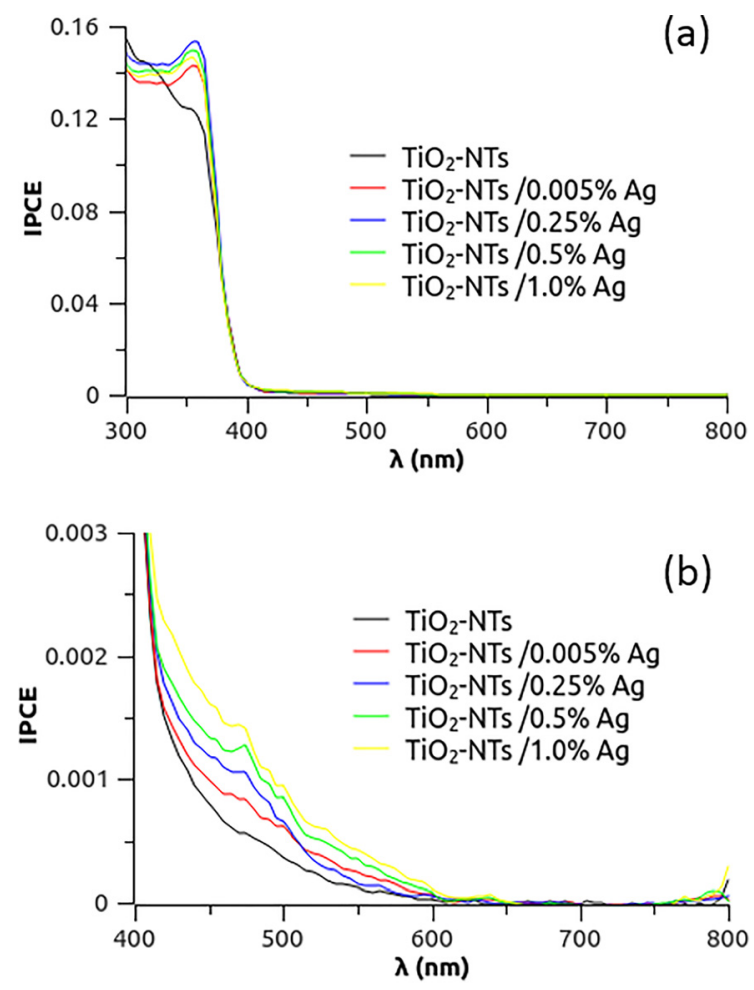

FIG. 4. IPCE curves for the $\mathrm{TiO}_{2}$ photoanode with increasing amount of deposited Ag (a). Zoom in the region were the activities in the visible light increases with the increasing loading of $\mathrm{Ag}(\mathrm{b})$. Applied potential is $0.168 \mathrm{~V}$ vs. $\mathrm{RHE}, \mathrm{pH}=10$. and the $\mathrm{Ag}$ nanoparticles are perfectly spherical and from identical size. On the contrary, in the experimental case, the tube surfaces are rough and the Ag nanoparticles can have a slightly non-spherical shape and have a size distribution.

Nevertheless, as shown in Fig. 4(b), in the region where the SPR of the Ag nanoparticles is maximum, the IPCE increases with the amount of deposited $\mathrm{Ag}$ up to $0.17 \%$ at $450 \mathrm{~nm}$ for the sample $\mathrm{TiO}_{2}-\mathrm{NTs} / 1.0 \% \mathrm{Ag}$. This observation is in good accordance with the absorption results from Fig. $3(\mathrm{a})$, meaning that the visible light absorbed by the $\mathrm{Ag} / \mathrm{TiO}_{2}$ system is converted into current. As on the absorption spectra, the main IPCE edge of $\mathrm{TiO}_{2}$ is not red shifted, meaning that the presence of $\mathrm{Ag}$ does not reduce its band gap. Nevertheless, one can see that the unmodified $\mathrm{TiO}_{2}-\mathrm{NTs}$ have a non-zero IPCE in the visible region. This small activity can be attributed to the presence of surface states and/or oxygen vacancies located above the valence band of $\mathrm{TiO}_{2}$. It is possible that it is that activity that is amplified by the near field electromagnetic and scattering mechanisms of the surface plasmon resonance of the $\mathrm{Ag}$ nanoparticles, as explained by Linic et $a l^{20}$

In summary, the deposition of $\mathrm{Ag}$ nanoparticles, with controlled size and shape, which have a surface plasmon resonance centered at $400 \mathrm{~nm}$, on the surface of vertically aligned $\mathrm{TiO}_{2}$-NTs, induces visible light absorption, up to $440 \mathrm{~nm}$, due to the modification of the dielectric constant of the environment surrounding the nanoparticles. The proposed FDTD model, designed from the experimental observations, confirms this behavior by exhibiting similar red shift in the position of the surface plasmon resonance in the $\mathrm{Ag}$ nanoparticles when deposited on $\mathrm{TiO}_{2}$.

The $\mathrm{Ag} / \mathrm{TiO}_{2}$-NT system was used as photoanode in a photoelectrochemical water splitting experiment, and its activity has been measured in terms of IPCE. The red shifted surface plasmon resonance of the $\mathrm{Ag}$ nanoparticles induces an increase in activity under visible light, which tends to increase with the amount of deposited Ag.

The increased activity induced by $\mathrm{Ag}$ is located in the same region as the one usually observed for anionic doped or co-doped $\mathrm{TiO}_{2}$ materials. ${ }^{33}$ This means that the Ag nanoparticles could be deposited on the doped or co-doped $\mathrm{TiO}_{2}$ based nanomaterials to further increase their activity under visible light. These results gave interesting information for understanding the behavior of surface plasmon enhanced light converting setups such as solar cells and photoelectrocatalytic systems.

See supplementary material for all the experimental details concerning the preparation of the vertically aligned $\mathrm{TiO}_{2}$ nanotubes and the $\mathrm{Ag}$ nanoparticles.

The authors would like to acknowledge the contribution of Loic Vidal (IS2M) and Thierry Romero (ICPEES) for the SEM and TEM imaging.

${ }^{1}$ D. Gong, C. A. Grimes, O. K. Varghese, W. Hu, R. S. Singh, Z. Chen, and E. C. Dickey, J. Mater. Res. 16(12), 3331-3334 (2001).

${ }^{2}$ V. Zwilling, E. Darque-Ceretti, A. Boutry-Forveille, D. David, M. Y. Perrin, and M. Aucouturier, Surf. Interface Anal. 27(7), 629-637 (1999).

${ }^{3}$ A. Ghicov and P. Schmuki, Chem. Commun. 2009, 2791.

${ }^{4}$ A. Fujishima and K. Honda, Nature 238(5358), 37-38 (1972). 
${ }^{5}$ S. T. Nishanthi, S. Iyyapushpam, B. Sundarakannan, E. Subramanian, and D. Pathinettam Padiyan, Appl. Surf. Sci. 313, 449-454 (2014).

${ }^{6}$ B. Yuan, Y. Wang, H. Bian, T. Shen, Y. Wu, and Z. Chen, Appl. Surf. Sci. 280, 523-529 (2013).

${ }^{7}$ Y.-C. Nah, I. Paramasivam, and P. Schmuki, Chem, Phys. Chem. 11(13), 2698-2713 (2010).

${ }^{8}$ W.-J. Yin, H. Tang, S.-H. Wei, M. M. Al-Jassim, J. Turner, and Y. Yan, Phys. Rev. B 82(4), 45106 (2010).

${ }^{9}$ M. Grätzel, Nature 414(6861), 338-344 (2001).

${ }^{10}$ J. Luo, Y. Ma, H. Wang, and J. Chen, Electrochim. Acta 167, 119-125 (2015).

${ }^{11}$ K. R. Reyes-Gil and D. B. Robinson, ACS Appl. Mater. Interfaces 5(23), 12400-12410 (2013).

${ }^{12}$ M. Rycenga, C. M. Cobley, J. Zeng, W. Li, C. H. Moran, Q. Zhang, D. Qin, and Y. Xia, Chem. Rev. 111(6), 3669-3712 (2011).

${ }^{13}$ D. B. Ingram and S. J. Linic, Am. Chem. Soc. 133(14), 5202-5205 (2011).

${ }^{14}$ W. Hou and S. B. Cronin, Adv. Funct. Mater. 23(13), 1612-1619 (2013).

${ }^{15}$ Z. Liu, W. Hou, P. Pavaskar, M. Aykol, and S. B. Cronin, Nano Lett. 11(3), 1111-1116 (2011).

${ }^{16}$ S. S. Rayalu, D. Jose, M. V. Joshi, P. A. Mangrulkar, K. Shrestha, and K. Klabunde, Appl. Catal., B 142-143, 684-693 (2013).

${ }^{17}$ J. Yi, S. Zhang, H. Wang, H. Yu, and F. Peng, Mater. Res. Bull. 60, 130-136 (2014).

${ }^{18}$ P. A. Gross, S. N. Pronkin, T. Cottineau, N. Keller, V. Keller, and E. R. Savinova, Catal. Today 189(1), 93-100 (2012).
${ }^{19}$ A. O. Govorov, H. Zhang, and Y. K. Gun'ko, J. Phys. Chem. C 117(32), 16616-16631 (2013).

${ }^{20}$ S. Linic, P. Christopher, and D. B. Ingram, Nat. Mater. 10(12), 911-921 (2011).

${ }^{21}$ K. Yee, IEEE Trans. Antennas Propag. 14(3), 302-307 (1966).

${ }^{22}$ D. Regonini, C. R. Bowen, A. Jaroenworaluck, and R. Stevens, Mater. Sci. Eng., R 74(12), 377-406 (2013).

${ }^{23}$ G. K. Mor, O. K. Varghese, M. Paulose, K. Shankar, and C. A. Grimes, Sol. Energy Mater. Sol. Cells 90(14), 2011-2075 (2006).

${ }^{24}$ J. M. Macak, H. Tsuchiya, A. Ghicov, K. Yasuda, R. Hahn, S. Bauer, and P. Schmuki, Curr. Opin. Solid State Mater. Sci. 11(1-2), 3-18 (2007).

${ }^{25}$ S. E. Skrabalak, B. J. Wiley, M. Kim, E. V. Formo, and Y. Xia, Nano Lett. 8(7), 2077-2081 (2008).

${ }^{26}$ S. Komarneni, H. Katsuki, D. Li, and A. S. Bhalla, J. Phys.: Condens. Matter 16(14), S1305-S1312 (2004).

${ }^{27}$ A. B. Murphy, J. Phys. Appl. Phys. 39(16), 3571-3581 (2006).

${ }^{28}$ J. Tauc, R. Grigorovici, and A. Vancu, Phys. Status Solidi B 15(2), 627-637 (1966).

${ }^{29}$ D. Yang, Y. Sun, Z. Tong, Y. Tian, Y. Li, and Z. Jiang, J. Phys. Chem. C 119(11), 5827-5835 (2015).

${ }^{30}$ P. B. Johnson and R.-W. Christy, Phys. Rev. B 6(12), 4370 (1972).

${ }^{31}$ K. Sivaiah, Mater. Sci. Appl. 2(11), 1688-1696 (2011).

${ }^{32}$ M. Landmann, E. Rauls, and W. G. Schmidt, J. Phys.: Condens. Matter 24(19), 195503 (2012).

${ }^{33}$ T. Cottineau, N. Béalu, P.-A. Gross, S. N. Pronkin, N. Keller, E. R. Savinova, and V. Keller, J. Mater. Chem. A 1(6), 2151-2160 (2013). 